\title{
Lymphomatoid Papulosis Misdiagnosed as Anaplastic Lymphoma
}

Caius Solovan ${ }^{1,2}$ and Flavia Baderca ${ }^{3,4^{*}}$

${ }^{1}$ Dermatology, "Victor Babeş" University of Medicine and Pharmacy, Timișoara, Romania

${ }^{2}$ Department of Dermatology, Emergency City Hospital, Timișoara, Romania

${ }^{3}$ Department of Microscopic Morphology, "Victor Babeş" University of Medicine and Pharmacy, Timișoara, Romania

${ }^{4}$ Service of Pathology, Emergency City Hospital, Timișoara, Romania

"Corresponding author: Flavia Baderca, Associate Professor, Department of Microscopic Morphology, "Victor Babeş" University of Medicine and Pharmacy, 2 Eftimie Murgu Square, 300077 Timişoara, Romania, Tel: +40733-106-101; E-mail: flaviabaderca@yahoo.com

Received date: February 15, 2016; Accepted date: April 15, 2016; Published date: April 25, 2016

Copyright: @ 2016 Solovan C, et al. This is an open-access article distributed under the terms of the Creative Commons Attribution License, which permits unrestricted use, distribution, and reproduction in any medium, provided the original author and source are credited.

\begin{abstract}
Lymphomatoid papulosis is a very rare skin disorder, defined as a chronic, recurrent, self-healing papulonodular or papulonecrotic skin eruption with suggestive histopathological features of a cutaneous lymphoma. We report a case of a 47-year-old male with an 8 years history of recurrent papulonodular lesions, some ulcerated, located on the face, trunk and extremities. The patient has been diagnosed primary with staphylococcal infection based on the clinical features and then, after a skin biopsy with anaplastic large cell lymphoma with CD30 positive cells and treated with CHOP. When he stopped the therapy, the lesions reappeared. A second skin biopsy was performed. Histological examination revealed an infiltrate of dyscohesive atypical lymphoid cells at the dermal-epidermal junction extending in the deep dermis. These atypical lymphoid cells varied in size and had pale abundant cytoplasm. Mitoses including atypical forms were prominent. Small mature appearing lymphocytes admixed with neutrophils and eosinophils were scattered throughout the tumor. Immunohistochemical studies demonstrated that the atypical lymphoid cells expressed $\mathrm{CD} 30, \mathrm{Bcl}-2$ and $\mathrm{Ki}-67$ (90\%). Considering also the clinicopathological correlation, the morphological and immunohistochemical stains were suggestive for the diagnosis of lymphomatoid papulosis type $\mathrm{A}$.
\end{abstract}

\section{Keywords: Lymphomatoid papulosis; CD30+ cutaneous Material and Methods}

lymphoproliferative disorder

\section{Introduction}

Lymphomatoid papulosis is a rare skin disorder that is characterised by crops of self healing skin lesions that look cancerous under the microscope but are actually benign (non-malignant). Lesions contain unusual cells that are similar to those found in some lymphomas (cancers of the lymphatic system).

Lymphomatoid papulosis is a very rare skin disorder, defined as a chronic, recurrent, self-healing papulonodular or papulonecrotic skin eruption [1] with suggestive histopathological features of a cutaneous lymphoma [2]. The incidence is $1.2-1.9$ cases per million, occurring sporadically in both sexes from childhood to old age, the average age being 40 [1]. The neoplastic cell is typically a CD4+ lymphocyte also manifesting CD30 expression [3]. Three major histological types were described: A, B and C. The infiltrate in A and C pattern is positive for CD30, whereas lymphomatoid papulosis type B is composed of pleomorphic irregular, enlarged and hyperchromatic lymphocytes, CD30 negative, showing epidermotropism and resembling classic mycosis fungoides [4]. Recently, newly variants were proposed: type D, variant simulating histologically an aggressive epidermotropic CD8positive T-cell lymphoma, type $\mathrm{E}$ with no cutaneous spread and excellent prognosis and a folliculotropic variant, type $\mathrm{F}$. The type $\mathrm{E}$ should exclude forms of angiodestructive and angiocentric cytotoxic $\mathrm{T}$ cell lymphoma $[5,6]$.
In this study, we report a case of a 47 -year-old male who presented to the Dermatology and Venereology Department of Timisoara's Emergency City Hospital describing an 8 years history of recurrent papulonodular lesions.

Before the presentation in the Dermatology department of our hospital, the patient has been diagnosed primary with staphylococcal infection based on the clinical features and consequently, after a skin biopsy, with anaplastic large cell lymphoma CD30+ and treated with CHOP. Once the patient stopped the therapy, the lesions reappeared.

Because of the clinical appearance of the lesions, we decided to perform a new biopsy.

The specimens for histopathological evaluation were obtained by incisional biopsy, fixed in $4 \% \mathrm{v} / \mathrm{v}$ buffered formalin and sent to the Pathology Service of the same hospital. The fixed tissues fragments were embedded in paraffin and prepared through classically histological technique.

For diagnostic purpose, three micrometers serial sections were initially stained with hematoxylin and eosin. While reading the slides, the pathologists paid attention to the histological type of the cells, cellular and nuclear pleomorphism, and mitotic count, distribution of the cellular infiltrate and presence or absence of epidermotropism.

Additional immunohistochemical stains for different markers were performed (B-cell [CD20, CD79], T-cell [CD3, CD4, CD5, CD7, CD8, UCHL], cell cycle markers [bcl-2, bcl-6], cell proliferation [Ki67]) were 
Citation: Solovan C, Baderca F (2016) Lymphomatoid Papulosis Misdiagnosed as Anaplastic Lymphoma. J Cytol Histol 7: 415. doi:

Page 2 of 4

performed using the protocol of the antibodies producer (Novocastra Reagents and Antibodies: Leica Biosystems, New Castle, UK).

The slides were visualized using a Leica DM750 microscope and the pictures were captured with a DMShare System from Leica Biosystems, New Castle, UK.

\section{Results}

At the time of presentation in our clinic, the lesions, some ulcerated, were located on the face (Figure 1), trunk and extremities.

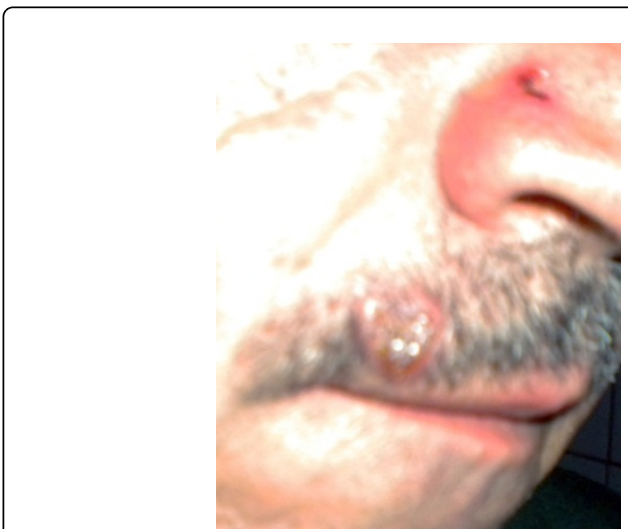

Figure 1: Lymphomatoid papulosis: clinical aspect of an ulcerated facial nodules.

General physical examination did not evidence hepatosplenomegaly, peripheral lymphadenopathy and additional investigations excluded extracutaneous involvement. A new skin biopsy was performed.

Histopathological examination on morphological stained slides revealed an infiltrate of dyscohesive atypical lymphoid cells at the dermal-epidermal junction extending to the deep dermis and subcutaneous fat. The overlying epidermis was ulcerated, being covered with neutrophilic detritus and keratotic crust.

In the dermis, the atypical lymphoid cells were present in large sheets, predominantly around some small vessels (arterioles) with lesions of necrotizing vasculitis. They varied in size and had pale abundant cytoplasm. Nuclei were irregularly shaped, vesicular and pleomorphic. One or multiple, prominent nucleoli were noted. Mitoses including atypical forms were prominent. Small mature appearing lymphocytes admixed with neutrophils, and eosinophils were scattered throughout the tumor (Figures 2-5).

A diagnosis of lymphomatoid papulosis was made. The patient had a favorable outcome with totally remission of the lesions without treatment, shortly after the diagnosis. Even if the patient reported selfhealing of the lesions, unfortunately, after several months, recurrent, erythematous papules and nodules appeared on the face, trunk, and extremities, apparently not related to other factors.

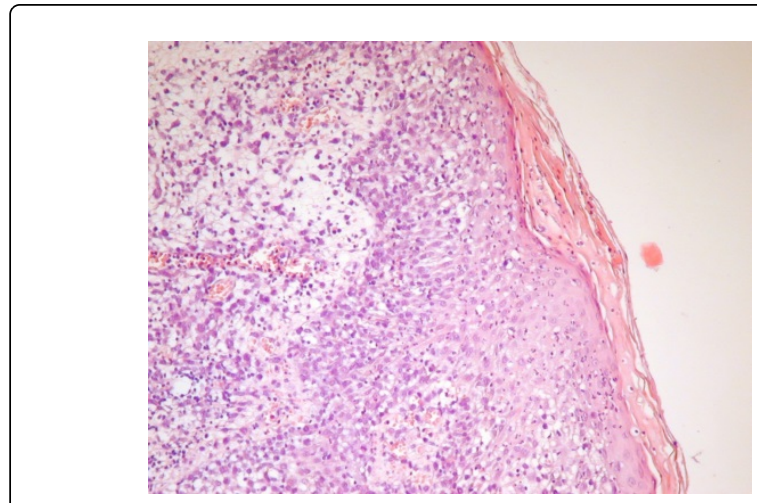

Figure 2: Lymphomatoid papulosis: infiltrate of atypical lymphoid cells admixed with neutrophils, eosinophils and large pale cells (H\&E stain, ob. 10x).

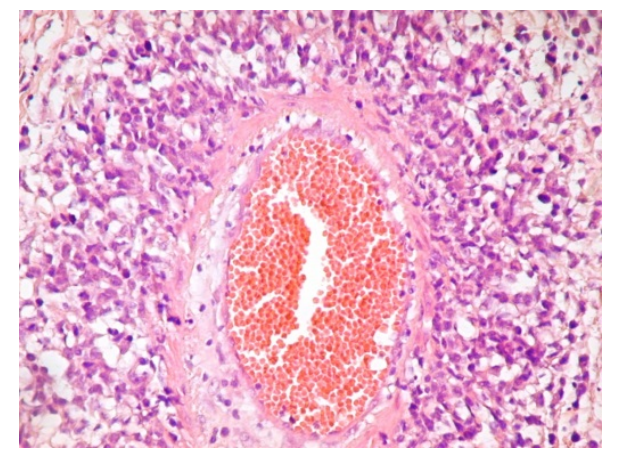

Figure 3: Lymphomatoid papulosis: in the dermis the atypical lymphoid cells are present in large sheets, predominantly around some small vessels (arterioles) with lesions of necrotizing vasculitis (H\&E stain, ob. 20x).

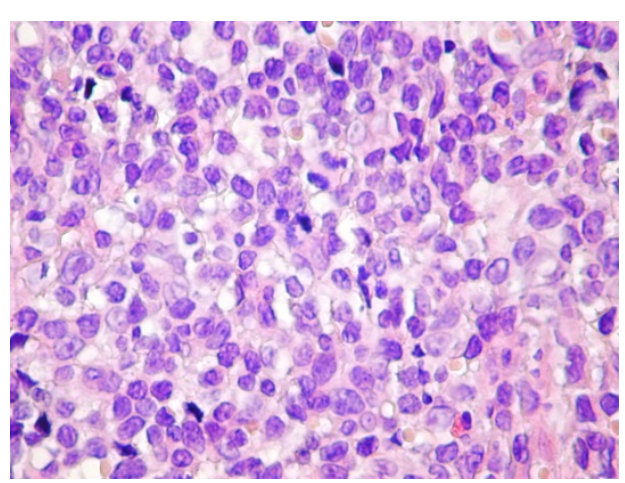

Figure 4: Lymphomatoid papulosis: the cells vary in size and have pale abundant cytoplasm; the nuclei are irregularly shaped, vesicular and pleomorphic; one or multiple prominent nucleoli are noted; mitotic figures are present (H\&E stain, ob. 40x). 


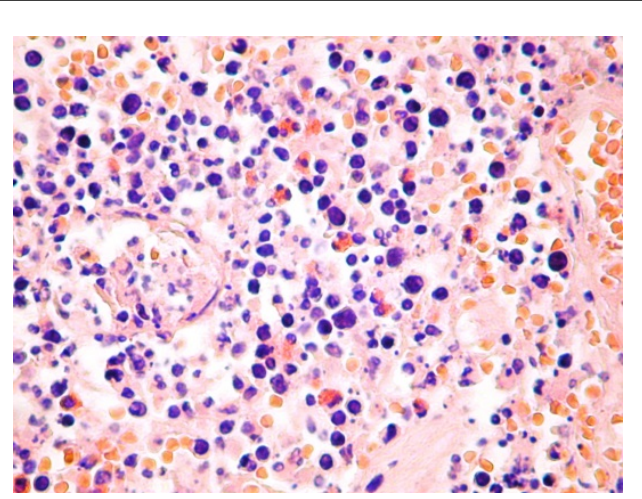

Figure 5: Lymphomatoid papulosis: small mature appearing lymphocytes, neutrophils, and eosinophils scattered throughout the lesion (H\&E stain, ob. 40x).

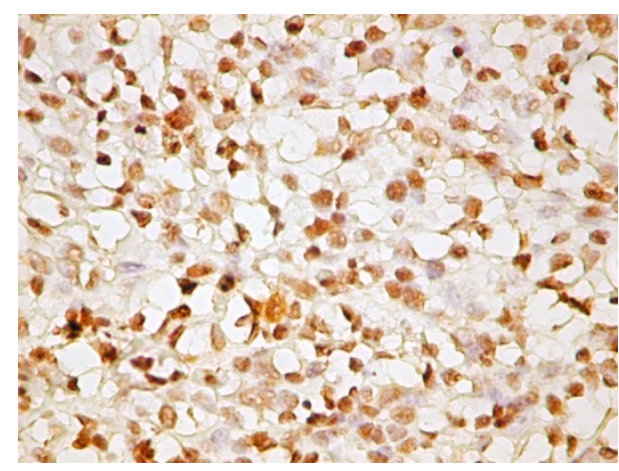

Figure 6: Lymphomatoid papulosis: numerous $\mathrm{CD} 30+$ cells are present (ob. 40x).

Immunohistochemical studies demonstrated that the atypical lymphoid cells expressed CD30 and bcl-2. The mitotic index, highlighted by Ki67 immunolabeling was 90\% (Figure 6).

A diagnosis of lymphomatoid papulosis was made. The patient had a favorable outcome with totally remission of the lesions without treatment, shortly after the diagnosis. Even if the patient reported selfhealing of the lesions, unfortunately, after several months, recurrent, erythematous papules and nodules appeared on the face, trunk, and extremities, apparently not related to other factors.

\section{Discussion}

Lymphomatoid papulosis is a chronic eruption of papules and nodules with spontaneously regression. Only in $10-20 \%$ of cases is associated with another lymphoma, usually mycosis fungoides, anaplastic large cell lymphoma or Hodgkin's lymphoma, that can precede, be concomitant or follow the disease [7]. Also, these patients are at higher risk to develop a second non-lymphoid malignancies [8].

Clinically, lesions coexist in different developmental stages and can heal in weeks or months, leaving areas of hyperpigmentation, hypopigmentation or scarring. Involvement of mucous membranes is uncommon $[9,10]$.
Histological aspects of lymphomatoid papulosis are variable. There were described six histological types. Classically, there are three types of lymphomatoid papulosis recognized today A, B, and C; other three types (D, E and F) are under discussion to be confirmed as distinct subtypes.

Type A is the most common entity and is characterized by the presence of large atypical cells, scattered or clustered admixed with small lymphocytes, neutrophils, histiocytes and eosinophils.

Variant B histological features are similar with those of mycosis fungoides and the diagnosis of lymphomatoid papulosis is established by clinicopathological correlation. The infiltrate of type B has been reported being CD30 negative [4].

The histological findings in type $\mathrm{C}$ resemble with those of cutaneous anaplastic large cell lymphoma.

In type D lesions, atypical lymphoid cells express positivity for CD8 and CD30. Differential diagnosis of type $\mathrm{D}$ must rule out primary cutaneous aggressive epidermotropic CD8+ cytotoxic T-cell lymphoma and

Diagnosis of type E of lymphomatoid papulosis should exclude forms of angiodestructive and angiocentric cytotoxic $\mathrm{T}$ cell lymphoma $[5,6]$.

Recently, a folliculotropic variant of lymphomatoid papulosis, which involves the hair follicles, was described. Histological characteristics of this form reveal medium to large atypical lymphoid cells CD30+ with a perifollicular pattern and variable degree of folliculotropism, which can mimic folliculotropic variant of mycosis fungoides [11,12].

Differential diagnosis of lymphomatoid papulosis includes pityriasis lichenoides et varioliformis acuta (PLEVA), reactions to arthropod bites, nodular scabies, cutaneous viral infection, lymphomatoid drug eruptions [4]. Lymphomatoid papulosis prognosis is excellent and the expected 5-year survival is almost $100 \%$ [13]. Some patients may have few recurrences of the disease over the years, and others may have lesions appearing almost continuously. Because $10-20 \%$ of cases develop an associated malignancy, regular follow-up is necessary. The patient presented in this study had a favorable outcome, typical for lymphomatoid papulosis, with totally remission of the lesions shortly after our evaluation.

\section{Conclusion}

This study highlighted the importance of the clinicopathological correlation in order to pronounce a correct diagnosis for the patients with CD30 positive lymphoproliferative disorders. These atypical lymphoid cells varied in size and had pale abundant cytoplasm. Mitoses including atypical forms were prominent. Small mature appeared lymphocytes admixed with neutrophils and eosinophils were scattered throughout the tumor. Immunohistochemical studies demonstrated that the atypical lymphoid cells expressed CD30, Bcl-2 and $\mathrm{Ki}-67$ (90\%). Considering also the clinicopathological correlation, the morphological and immunohistochemical stains were suggestive for the diagnosis of lymphomatoid papulosis type A.

\section{Acknowledgments}

This work was supported by the project "From chronic inflammatory dermatoses to cutaneous lymphoma: molecular cytogenetic and gene expression profiling" with number IZERZ0_142305, from the UEFISCDI Romania in collaboration with 
Citation: Solovan C, Baderca F (2016) Lymphomatoid Papulosis Misdiagnosed as Anaplastic Lymphoma. J Cytol Histol 7: 415. doi: 10.4172/2157-7099.1000415

Page 4 of 4

Romanian Minister of Education, Science, Youth and Sport, "Victor Babes" University of Medicine and Pharmacy and FNSNF - Swiss National Science Foundation under the auspice of Romanian-Swiss Research Programme (RSRP).

\section{References}

1. Bolognia JL, Jorizzo JL, Rapini RP (2008) Dermatology, Ch. Primay Cutaneous CD30+ Lymphoproliferative Disorders p: 1878

2. Burg G, Kempf W (2005) Cutaneous lymphomas, Ch. Lymphomatoid papulosis p: 165

3. Tan SH, Sim CS, Ong BH (2003) Cutaneous lymphomas other than mycosis fungoides in Singapore: a clinicopathological analysis using recent classification systems. Br J Dermatol 149: 542-553.

4. McKee PH, Calonje E, Granter SR (2005) Pathology of the skin. (3rdedn) Ch Cutaneous lymphoproliferative disease and related disorders pp: 1401-1402

5. Kempf W, Kazakov DV, Schärer L, Rütten A, Mentzel T, et al. (2013) Angioinvasive lymphomatoid papulosis: a new variant simulating aggressive lymphomas. Am J Surg Pathol 37: 1-13

6. Cardoso J, Duhra P, Thway Y, Calonje E (2012) Lymphomatoid papulosis type D: a newly described variant easily confused with cutaneous aggressive CD8-positive cytotoxic T-cell lymphoma. Am J Dermatopathol 34: $762-765$.
7. Basarab T, Fraser-Andrews EA, Orchard G, Whittaker S, Russell Jones R (1998) Lymphomatoid papulosis in association with mycosis fungoides: a study of 15 cases. Br J Dermatol 139: 630-638.

8. Wang HH, Myers T, Lach LJ, Hsieh CC, Kadin ME (1999) Increased risk of lymphoid or non-lymphoid malignancies in patients with lymphomatoid papulosis. Cancer 86: 1240-1245.

9. Chimenti S, Fargnoli MC, Pacifico A, Peris K (2001) Mucosal involvement in a patient with lymphomatoid papulosis. J Am Acad Dermatol 44: 339

10. Kato N, Tomita Y, Yoshida K, Hisai H (1998) Involvement of the tongue by lymphomatoid papulosis. Am J Dermatopathol 20: 522.

11. Kempf W, Kazakov DV, Baumgartner HP, Kutzner H (2013) Follicular lymphomatoid papulosis revisited: A study of 11 cases, with new histopathological findings. J Am Acad Dermatol 68: 809-816.

12. Karai LJ, Kadin ME, Hsi ED, Sluzevich JC, Ketterling RP, et al. (2013) Chromosomal Rearrangements of 6p25.3 Define a New Subtype of Lymphomatoid Papulosis. Am J Surg Pathol 37: 1173-1181.

13. Fink-Puches R, Zenahlik P, Bäck B, Smolle J, Kerl H, et al. (2002) Primary cutaneous lymphomas applicability of current classification schemes (European Organization for Researche and Treatment of Cancer, World Health Organization) based on clinicopathologic features observed in a large group of patients. Blood 99: 800-805. 